\title{
NOTES AND OBSERVATIONS
}

DETERMINATION OF THE FIRST CONTACT OF THE SOLAR ECLIPSE OF OCTOBER 12, 1958

This eclipse was seen in Chile near sunset, under exceptionally good weather conditions. At our Observatory $\left(\lambda=4^{\mathrm{h}} 42^{\mathrm{m}} 44^{\mathrm{s}} 4, \varphi=-33^{\circ} 33^{\prime} 40^{\prime \prime}\right.$, $\mathrm{h}=568 \mathrm{~m}$ ) the first contact was determined from a sequence of fourteen photographs (diameter of the image $=2 \mathrm{I} \mathrm{mm}$ ) taken by A. Gutiérrez within an interval of $2^{\mathrm{m}} 25^{\mathrm{s}}$ after the contact.

The chords were measured and the reductions made independently by A. Gutiérrez and G. Romero, by means of Danjon's method.
The final results are:

$\begin{array}{lccc}\text { Computer } & \mathrm{T}_{1}(\mathrm{UT}) & \text { m.e. } & \begin{array}{c}\text { Sets of } \\ \text { measures }\end{array} \\ \text { Gutiérrez } & 2 \mathrm{I}^{\mathrm{h}} 35^{\mathrm{m}} 20 . \mathrm{I} & \pm 0.2 & 3 \\ \text { Romero } & 2 \mathrm{I} 3523.7 & \pm 0.7 & \mathrm{I}\end{array}$

A. Gutiḱrrez and G. Romero Astronomical Observatory University of Chile Santiago, Chile Received November 25, 1958

\section{ADDENDUM}

To Symposium on Planetary Radio Astronomy, Astronomical Journal 64, 37-48, 1959: This symposium was sponsored by the National Science Foundation. The Committee in charge of the symposium wishes to record an expression of thanks to the National Science Foundation for its support.

\section{NOTICES}

Monograph Prizes. The American Academy of Arts and Sciences will award annually three prizes of $\$ 1000$ each to the authors of especially meritorious unpublished monographs, one each in the fields of the Humanities, Social Sciences and Physical and Biological Sciences. For the purposes of these awards a Monograph is defined as a "scholarly contribution to knowledge, too long for an article in a learned journal and too specialized or too short for a general book." The final date in 1959 for receipt of manuscripts is October r. Full details may be secured on request from the Committee on Monograph Prizes, American Academy of Arts and Sciences, 280 Newton St., Brookline Station, Boston 46, Mass.

Kitt Peak National Observatory. Observing with the 36-telescope can probably begin about January 1960. In reply to several inquiries about observing time received to date, astronomers are informed that requests for use of the facilities, subject to unexpected delays, will be welcomed.

The 36-inch and the I6-inch telescopes will be equipped for UBV photometry with refrigerated photomultipliers. A classification spectrograph will be added to the 36 -inch shortly after January 1960. A ratio spectrometer is currently available on the I6-inch and a similar unit will soon be added to the 36 -inch.

Observing time can be assigned to a limited number of graduate students for Ph.D. thesis research. Subject to the availability of funds, travel expenses and subsistence will be granted to students.

Applications should be sent to the Director, Kitt Peak National Observatory, I033 North Park Ave., Tucson, Arizona. 